\title{
Industrial Attachment and Employability: Perspectives of Graphic Design Students and Industrial Supervisors
}

\author{
ABRAHAM BOAKYE - AMPONSAH \\ P o Box 256, Department of Graphics Technology, Takoradi Technical University \\ EBENEZER ENNINFUL \\ P o Box 256, Department of Graphics Technology, Takoradi Technical University \\ COLLINS KWASI FORDJOUR \\ P o Box 256, Department of Graphics Technology, Takoradi Technical University
}

\begin{abstract}
To provide students with career focused tertiary education that enhances employability for middle-level supervisory and managerial positions in business and industry in Ghana, the Polytechnic Act 2007, Act 754, was enacted. This Act makes it mandatory for all students to undertake Industrial Attachment. The focus of Industrial Attachment is to help enhance graduate employability through the acquisition of employable skills and knowledge, to assist students to build or improve their personal skills to increase their chances of obtaining secured jobs in their respective fields of study and to be able to contribute meaningfully to economic growth and national development (Walker II, 2011; Nunfam et al 2015). Although Graphic Design students spend six months (on different vacation periods) out of the total three years on the HND Programme on Industrial Attachment, yet most of them find it difficult to obtain jobs relating to their area of specialities, while some of those employed in the Graphic Design industry also lack the needed industrial skills to enable them to perform effectively (Nunfam et al 2015). The aim of this paper was to explore and describe the extent to which Graphic Design students of the Takoradi Technical University are equipped with industrial experience and practical skills through Industrial Attachment to enhance employability. Mixed research strategy (Qualitative and Quantitative) was employed. A case study research design was used, and research instruments employed to obtain data were survey questionnaire and interview for the collection of qualitative and quantitative data to answer the research question: What are the perceptions of students and industrial supervisors on the impact of Industrial Attachment on employability? Purposive sampling technique was used to select a sample of 217 respondents, made up of 209 level 300 students and 8 industrial supervisors.Qualitative data was analysed through thematic analysis and quantitative data was also analysed with SPSS statistics software. Students have good understanding of theoretical knowledge. However, due to ineffective collaboration between Takoradi Technical University and the various industries, and the lack of effective strategic management of the Industrial Attachment programme, some students have limited practical skills. Collaboration between Takoradi Technical University and industries is critical for the development of employability skills. For Graphic Design students to benefit from the Industrial Attachment programme, all stakeholders of Takoradi Technical University need to put in the technical expertise, resources, infrastructure, incentives and motivations to foster a seamless partnership between the University and the industries. Also, the current inadequate Industrial Attachment programme requires a critical evaluation through effective strategic management.
\end{abstract}

Keywords: Technical University Education, Industrial attachment, Graphic Design, Employability skills.

DOI: $10.7176 / \mathrm{JEP} / 11-18-10$

Publication date:June 30th 2020

\section{Introduction}

Technical University (Polytechnic) education according to Youssef and Hunter (2016), is a multidisciplinary tertiary education model in which students and industry are actively engaged in applied, lifelong learning and research, with the aims of promoting innovation and entrepreneurship to effect economically sustainable development on local, regional, and national levels. They further explain that this model provides students with a variety of credentials and workplace-ready knowledge, skills and experience that consolidates theory and practice (Youssef \& Hunter 2016).

Polytechnic Canada (2007) defines, Technical University (Polytechnic) Education as a profession-focused on applied education that covers trades from apprenticeship to diplomas, certificates, Applied Bachelor's degrees and Master's degrees, which are provided in a hands-on training environment that give students the opportunity to readily apply their practical skills (Doern, 2008).

Hands-on training that combines theory and practical is referred to as Technical University Education started in France in 1794, and has been accepted and hailed worldwide as the best way to promote innovation and entrepreneurship for effective economic development. Countries such as Switzerland, USA, Russia, Finland, 
Hong Kong, UK, South Africa, Ghana and many others have also adopted the French Technical Education (Polytechnic) model, designed to prepare the labour force by combining teaching and learning about the economic production with practical work experience (Robinson 2012; Youssef and Hunter 2016).

Technical University (Polytechnic) education and industrial attachment have therefore been acknowledged worldwide as an important vehicle to drive employability, economic growth and national development (Youssef 2016; Kwami 2001). To achieve this in Ghana, the Polytechnic Act, 2007, Act 754 was enacted in 2007 to provide tertiary education that is career focused. Kwami (2001) describes polytechnics as technological institutions with the sole responsibility of contributing actively to national development by providing careerfocused education and skills training to the highest level possible and providing opportunities for applied research with close collaboration with industry.

With the focus of Technical University (Polytechnic) education on the acquisition of both theory and practical knowledge for a smooth transition to industry, students are mandated to undertake a six months industrial attachment during the three-year HND programme. The objective is to expose them to employable skills and technologies not available at the University. This, according to the Ministry of Education, (1993) is to help make their training relevant to the job requirements of industry, build their confidence in technical operation, problem solving, team work as well as working with experienced professionals in the world of work. This was seen as the best way to provide higher level technician training and practical research (Ministry of Education, 1993).

To this end, the educational strategic plan for tertiary education (2010-2020) emphasized on the importance of an efficient and effective collaboration between tertiary education and industry to promote and review academic programmes and research relevant to national development in partnership with the private sector, and to undertake consultation with the private sector particularly industry, to help identify relevant areas for research which will promote development (Ministry of Education 2010 ).

Consequently, in his 2013 State of the Nation address, His Excellency, John Dramani Mahama, the President of the Republic of Ghana announced the conversion of Polytechnics to Technical Universities, with the aim of equipping students with high level technical skills to promote economic and national development, providing opportunities for company employees to upgrade their skills and acquire new skills and to contribute to the creation of a diverse and better performing higher education system (Ministry of Education 2014).

Since these laudable objectives of the government to upgrade the Polytechnics to Technical Universities does not solely depend on the theory knowledge provided by the Polytechnics, but with the active involvement of industry, it is very crucial to ascertain the part currently played by industry to effectively provide students with employable skills; for a smooth transition into industry to help fulfil Government employability aspirations for the Technical Universities.

Employability refers to the skills, understandings and personal attributes that make graduates more likely to gain employment and be successful in their chosen occupations to benefit themselves, the workforce, the community and the economy (Yorke 2004).

The arrival of global economy has changed the meaning of employment. Now the term employment is not only about training in a specific profession or getting a job but also keeping the job till retirement or during one's lifetime (Tin, 2006).

Hillage and Pollard (1998) define employability as an individual's ability to gain initial employment, maintain employment, move between different roles within an organisation, obtain new employment when necessary and secure appropriate and adequately satisfying work.

The theory of employability operates on the assumption that a degree is no longer enough to guarantee a graduate a satisfying future career (Peter Hawkins, 1999). Hence, it emphasises on how the job market is rapidly changing with new sectors emerging; changing the nature of work and the way employers perceive the workplace and how graduates will have to be flexible and have the personal capability to manage the changing and challenging work situations.

Employers are looking to recruit graduates who fit into the organisational culture and utilise their abilities and skills to transform the company by facilitating innovative teamwork (Harvey 2000a). This is even more true considering the current economic climate. Employability theorists argue that in many sectors, employers are looking for graduates who are ready to work, and have strong evidence of explicit job skills in addition to high level graduate attributes (Carbery \& Garavan, 2005). Therefore, to compete in the job market, students need to develop employability skills during their time at the university.

\section{Methodology}

To explore and describe the perceptions of Graphic Design students and Industrial supervisors on the effect of Industrial Attachment on employability, a mixed method research strategy was employed (quantitative and qualitative). This was used to help triangulate and compare results, overcome inherent weaknesses of both qualitative and quantitative research, to enhance the accuracy, validity and reliability of the study outcome and to 
provide a comprehensive picture of the identified problems for effective solution (Creswell et al 2003; Bryman 2016; Creswell \& Plano Clark 2011).

A case study design was chosen to assist in the collection of detailed and rich data (Hakim, 1987; Yin 1989). Purposive sampling was used for this study to assist researchers to quickly reach target sample who can provide relevant data to be explored to answer the research question (Creswell, 2012). Relevant population sample including 209 third year HND Graphic Design students and 8 Graphic Design industry supervisors were identified and assessed (Walliman, 2011).

Questionnaire was administered to 217 respondents, made up of 209 level 300 students, who have undertaken the six months Industrial Attachment programme, and 8 industrial supervisors who have been providing students with employable skills over the years. Questions included closed-ended and open-ended questions, to obtain qualitative and quantitative data. (Creswell \& Plano Clark, 2011).

Two sets of Data were collected for analysis. Whilst qualitative data was analysed through thematic analysis to help capture the complexities of meaning within the documented data, Statistical Package for Social Sciences (SPSS) was also used to analyse the quantitative data to obtain a descriptive statistic. Descriptive analysis was used to summarize the data, which was presented in Tables and expressed as percentages to make it meaningful and easy to understand. In total, eight Graphic Design firms in the Takoradi Metropolis, where students embark on Industrial Attachment were selected for the study. The companies were: Ajumakoman Press, Seven Colours, Esscolours, Dream Colours, Dream Pixels, Moonlight Photo Studio, Orbit and Joebio Press. The choice of these industries was to obtain relevant data from small and medium scale industries to help assess the impact of Industrial Attachment on student employability. Ethical approval was sought and obtained from the Managing Directors of the eight industries. Written consent was obtained from all participants. The study period was September - December 2018.

\section{Results}

Table 1: Knowledge of theory

\begin{tabular}{|l|c|c|}
\hline Statement & Frequency & Percentage (\%) \\
\hline I have good theory knowledge & 161 & 77 \\
\hline I have average knowledge & 48 & 23 \\
\hline I have limited knowledge & - & - \\
\hline Total & $\mathbf{2 0 9}$ & $\mathbf{1 0 0}$ \\
\hline
\end{tabular}

Source: Authors' Fieldwork (September, 2018)

From Table 1, it could be seen that about $77 \%$ of respondents believed they have acquired good theory knowledge and understanding of the curriculum. Evidence from Table 1 suggests that at the end of the three-year Graphic Design HND Programme, students felt they have acquired substantial theoretical knowledge from their study which provided them with detailed understanding of their area of study.

Table 2: Importance of theory in relation to practical skills

\begin{tabular}{|c|c|c|}
\hline Statement & Frequency & Percentage $(\%)$ \\
\hline Provides an insight into practical knowledge & 175 & 84 \\
\hline Prepares students for the acquisition of practical skills & 34 & 16 \\
\hline Total & 209 & 100 \\
\hline
\end{tabular}

Source: Authors' Fieldwork (September, 2018)

Information from Table 2 suggests that all respondents agreed that the theory knowledge acquired have provided important insight into the practical aspect of their course.

Table 3: Preparation and familiarization for Industrial Attachment

\begin{tabular}{|c|c|c|}
\hline Statement & Frequency & Percentage $(\%)$ \\
\hline I Had Industrial Attachment seminar from only the Polytechnic & 209 & 100 \\
\hline $\begin{array}{l}\text { I Had Industrial Attachment seminar from a combined team of the } \\
\text { Polytechnic and industry }\end{array}$ & - & - \\
\hline Total & 209 & 100 \\
\hline
\end{tabular}

Source: Authors' Fieldwork (September, 2018)

On the issue of effectively preparing students for Industrial Attachment, results from Table 3 suggest that, though the Polytechnic prepared students for Industrial Attachment, the preparation was one-sided as industry was not involved.

This shows that, preparing students for Industrial Attachment was woefully inadequate as industry was left out of the preparation process. 
Table 4: Awareness on the importance of Industrial Attachment on employability

\begin{tabular}{|l|c|c|}
\hline Statement & Frequency & Percentage (\%) \\
\hline $\begin{array}{l}\text { I knew about the benefit and impact of Industrial Attachment on } \\
\text { employability before my first Industrial Attachment }\end{array}$ & 209 & 100 \\
\hline $\begin{array}{l}\text { I did not know about the benefit and impact of Industrial Attachment } \\
\text { on employability before my first Industrial Attachment }\end{array}$ & - & - \\
\hline Total & $\mathbf{2 0 9}$ & $\mathbf{1 0 0}$ \\
\hline
\end{tabular}

\section{Source: Authors' Fieldwork (September, 2018)}

On the importance of Industrial Attachment in relation to employability, evidence from Table 4 suggests that respondents unanimously (100\%) agreed that, they knew about the benefits of Industrial Attachment and its impact on their employment after university. This suggests that though students have good knowledge of theory, they understand that theory alone is not adequate to provide them with employment and that the acquisition of employability skills was as equally important as the theory.

Table 5: Acquisition of suitable placement for Industrial Attachment

\begin{tabular}{|c|c|c|}
\hline Statement & Frequency & Percentage (\%) \\
\hline University allocate placement places & - & - \\
\hline Students find placements by themselves & 209 & 100 \\
\hline Total & 209 & 100 \\
\hline
\end{tabular}

Source: Authors' Fieldwork (September, 2018)

From Table 5, respondents unanimously stated that, they had to look for organisations to undertake Industrial Attachment (100\%). This result suggests that all respondents had to look for an Industry to train without the help of the University. Though the University might have been in touch with some of the industries and provide students with introduction letters, these measures were not adequate to ease the difficulty respondents go through when looking for a place to be trained.

Table 6: Students' opinion on the benefits derived from Industrial Attachment

\begin{tabular}{|l|c|c|}
\hline Statement & Frequency & $\begin{array}{c}\text { Percentage } \\
(\%)\end{array}$ \\
\hline $\begin{array}{l}\text { Had opportunity to handle and work with most industrial tools, materials and } \\
\text { equipment }\end{array}$ & 121 & 57.9 \\
\hline Had opportunity to handle limited industrial tools, materials and equipment & 88 & 42.1 \\
\hline Total & $\mathbf{2 0 9}$ & $\mathbf{1 0 0}$ \\
\hline
\end{tabular}

Source: Authors' Fieldwork (September, 2018)

Information from Table 6 indicates that more than half of respondents $(57.9 \%)$ had the opportunity to work with most industrial tools, materials and equipment, with $42.1 \%$ having access to limited use of industrial tools, materials and equipment during the entire 9 months Industrial Attachment.

Table 7: Students opinion on the acquisition of work experience

\begin{tabular}{|c|c|c|}
\hline Statement & Frequency & Percentage (\%) \\
\hline Acquired a lot of work experience & 121 & 57.9 \\
\hline Acquired limited work experience & 88 & 42.1 \\
\hline Total & 209 & 100 \\
\hline
\end{tabular}

Source: Authors' Fieldwork (September, 2018)

In relation to the acquisition of work experience, results from Table 7 suggests that respondents who had the opportunity to work with many industrial tools, materials and equipment (as recorded in Table 6) had a lot of work experience. While those with limited use of industrial tools, materials and equipment had limited work experience.

Table 8: Students opinion on their chances of employment due to Industrial Attachment

\begin{tabular}{|l|c|c|}
\hline Statement & Frequency & Percentage (\%) \\
\hline Improved chance of Employment & 105 & 50.2 \\
\hline Did not improve chances of employment & 104 & 49.8 \\
\hline Total & $\mathbf{2 0 9}$ & $\mathbf{1 0 0}$ \\
\hline
\end{tabular}

Source: Authors' Fieldwork (September, 2018)

Results from Table 8 state that Industrial Attachment experience will enhance their chance of gaining employment $(50.2 \%)$, while $49.8 \%$ thought otherwise. This could be a cause for concern. Though about half of respondents felt they obtained employability skills, almost half of them felt that though they obtained some level of practical skills, it was not adequate to enhance their chances of employability. This suggests that students are not likely to gain employment after graduation, and will deny them the opportunity to contribute to national development and economic growth. 


\section{Industrial Supervisors}

Table 9: Industrial capacity and resources

\begin{tabular}{|c|c|c|}
\hline Statement & Frequency & Percentage (\%) \\
\hline Industry has adequate resources and capacity for Industrial Attachment & 3 & 37.5 \\
\hline Industry has limited resources and capacity for Industrial Attachment & 5 & 62.5 \\
\hline Total & 8 & 100 \\
\hline
\end{tabular}

Source: Authors' Fieldwork (September, 2018)

On the capacity and resources of industries for Industrial Attachment programme, only $37.5 \%$ indicated that they have enough resources and capacity with about $62.5 \%$ of industries lacking the necessary resources and capacity for effective industrial training for trainees.

Table 10: Scale of Industry

\begin{tabular}{|c|c|c|}
\hline Statement & Frequency & Percentage $(\%)$ \\
\hline I work in a large-scale industry & - & - \\
\hline I work in a medium-scale industry & 1 & 12.5 \\
\hline I work in a small-scale industry & 7 & 87.5 \\
\hline Total & 8 & 100 \\
\hline
\end{tabular}

\section{Source: Authors' Fieldwork (September, 2018)}

Evidence from Table 10 suggests that, only one out of the eight industries studied was a medium-scale industry, with more than 20 workers, while the remaining seven industries were small-scale in nature, with between 5 to 19 workers, as by the United Nations Industrial Development Organization (UNIDO, 2004) and the Ghana Statistical Service definition of small and medium industries in developing countries.

It was observed that most participants did their industrial training in small scale-industries with limited capacity, resources and specialities, due to the availability of a large number of small-scale Graphic Design industries. It could be suggested that participants who trained in these industries obtained limited employability skills that could hamper their chances of employment.

Table 11: Area (s) of Specialization

\begin{tabular}{|c|c|c|}
\hline Statement & Frequency & Percentage $(\%)$ \\
\hline We specialize in Pre-press, Press and post press & 2 & 25 \\
\hline We specialize in Pre-press\& press & 4 & 50 \\
\hline We specialize in Press & 1 & 12.5 \\
\hline We specialize in Photography & 1 & 12.5 \\
\hline Total & 8 & 100 \\
\hline
\end{tabular}

\section{Source: Authors' Fieldwork (September, 2018)}

From Table 11, it could be observed that $50 \%$ of members in the said industry specializes in pre-press and press, while $25 \%$ specialized in pre-press, press and post press, with $12.5 \%$ managing only press activities and another $12.5 \%$ engaged in Photography. This suggests that all students missed out on advertising and packaging firms.

Table 12: Industrial contribution to Industrial Attachment

\begin{tabular}{|c|c|c|}
\hline Statement & Frequency & Percentage $(\%)$ \\
\hline Provide students with adequate work experience & 2 & 25 \\
\hline Provide students with inadequate work experience & 4 & 50 \\
\hline Provide students with very limited work experience & 2 & 25 \\
\hline Total & 8 & 100 \\
\hline
\end{tabular}

Source: Authors' Fieldwork (September, 2018)

On the statement of industrial contribution to student work experience, half of supervisors (50\%) agreed that the industry provided students with practical skills and work experience. These responses suggest that, industry is aware of its contribution to Polytechnic education and understand the need to support and provide students with employability skills to attract employers.

Table 13: Willingness of industry to provide students with practical skills

\begin{tabular}{|c|c|c|}
\hline Statement & Frequency & Percentage $(\%)$ \\
\hline My industry is willing to impart knowledge and skills & 6 & 75 \\
\hline My industry is not willing to impart knowledge and skills & 2 & 25 \\
\hline Total & 8 & 100 \\
\hline
\end{tabular}

Source: Authors' Fieldwork (September, 2018)

From Table 13, though a good number of industries (75\%) are willing to accept students for Industrial Attachment, $25 \%$ of them are reluctant to do so. Reasons for their unwillingness need to be unearthed for solution. 


\section{DISCUSSION}

To ensure the acquisition of employability skills by Graphic Design students through Industrial Attachment, it was necessary to explore and understand the nature and forms of challenges obstructing the smooth provision of practical industrial skills to augment students' employability.

The importance and impact of Technical University education on the global economy and national development since the early nineteenth century cannot be overemphasized (Robinson 2012; Guimón 2013; Youssef \&Hunter 2014). For many years, governments around the world have initiated engagements between Technical Universities and industry with the primary aim of building partnership that could support their economies and promote national development (Walker II, 2011; Youssef \&Hunter 2014). As a result, industrial training of students by industry partners' form part of the Technical University curriculum, to equip students with valuable work skills, experience and opportunities to work with industry experts (Ayarkwa et al. 2012; Robinson 2012; Nunfam et al 2015).

This study identified two challenges hampering the effective acquisition of employability skills by students. These are ineffective collaboration between the Technical University and industry and lack of strategic management of the Industrial Attachment programme.

The need to build partnership and collaboration emerged as a central theme in the analysis of the qualitative data. All participants unanimously agreed on the importance of the University working closely with industry to help provide students with the practical skills and work experience they need to complete the HND programme and attract employers for employment. From the interview, participants argued that since the University does not have industrial equipment for teaching and learning, mutual working relationship building with industry is very crucial.

Some of the participants further explained that, though they have a wide range of theoretical knowledge as seen from Table 1, they need effective industrial experience to help them understand the theory, acquire practical skills, keep them abreast with the rapid technological advancement and to help them secure jobs. One participant explained that, "I see the Graphics Industry as a Graphics laboratory where we go for practical lessons after the abstract theory lectures at the University and that, just as a chemistry student cannot depend only on theory to gain employment as a chemical scientist, Graphic Design students cannot also depend only on theory knowledge to acquire employment, that is why Industrial Attachment is very important to us" (ST19). Results from Table 4, suggests that all participants view Industrial Attachment as an indispensable aspect of their course.

Drawing on employability theory, one participant argued that "Technical University Education comes in a package, made up of theory and practical. None of these, on its own is enough to produce a Graphic Design graduate worthy of employment by any employer" (ST102). For this reason, it is important for the University to work hand in hand with industry to effectively equip students with both theory and practical skills demanded by industry.

Boahin \& Hofman (2013) are of the view that, there is a wide gap between theoretical knowledge obtained by students at the Universities and the skills demanded by industry therefore, effective collaboration between the two is required to bridge the gap and augment employability of graduates (Lauber et al, 2004).

Evidence from studies suggest that, effective collaboration strengthens employer's involvement in the Technical Universities activities and in the entire educational process of preparing the students for employment in industry. It also enhances industry's satisfaction with the graduates of the Universities (Guimón 2013; Sorensen 2014; Youssef and Hunter 2016).

Guimón (2013) is of the view that, the world is progressively valuing the need for effective collaboration between academia and industry, as it is a crucial way to promote effective national innovation systems. Effective collaboration between University and industry is critical for skills development, innovation and technology transfer and the promotion of entrepreneurship (Guimón 2013).

Before students embark on Industrial Attachment, the University has the responsibility to engage industry to adequately prepare students for the practical training. However, results from Table 3 shows that, students were prepared for this important exercise by the University without the involvement of industry. This one-sidedpreparation of students for Industrial Attachment raises some concerns. In the first place, some of the things students might be told might not be currently relevant in industry due to the rapid technological advancement in the $21^{\text {st }}$ century. Secondly, they might not be able to provide students with appropriate answers or provide explicit explanations to questions they might ask during such seminars. To be fair to students, the industry must be involved in preparing them for Industrial Attachment to ensure that they are adequately prepared for the practical training. This problem could be attributed to ineffective collaboration between the University and industry.

From the data analysis, it was revealed that lack of effective University-Industry collaboration has resulted in the lack of trust in the whole programme, hence the unwillingness of some Graphics firms in the industry to accept or effectively train students on-the-job as seen from Table 13. According to one industrial supervisor, "The University does not discuss students training with us, we only see them when they come to see their 
students during their training" (SUP 3).

Results from Tables 6 and 7 respectively show that $42.1 \%$ of participants felt they had the opportunity to handle limited industrial tools, materials and equipment resulting in the acquisition of limited work experience; whereas results from Table 8 also suggests that, almost $50 \%$ of participants felt that the Industrial Attachment did not improve their chances of employment. It is very important for the Takoradi Technical University to value the need to effectively collaborate with every single industry involved in Industrial Attachment, as the current system of sending students to industries with only introduction letters is failing many students and calls for a new approach.

The University needs to realize that Industry employ ready-to-work graduates who are competent in industrial challenges after leaving the institution. Consequently, they need to have a special relationship with various players in the industry, listen to their concerns, study the business environment and respond appropriately to it, to enable the industry train students effectively for the job market (Robinson 2012).

In 2013, the report of the technical committee on the conversion of the Polytechnics in Ghana to Technical Universities stated that members of the committee visited some Universities in Germany and South Africa to learn from their upgrading systems.

They came out with a good report on how the Technical Universities should operate based on their observations on the system from the above-mentioned countries. Surprisingly, nothing was said about the nature and forms of industries in Germany or South Africa that helped Technical Universities to achieve their goals.

Researchers are of the view that, for Ghana Technical Universities to perform as their counterparts in Germany and South Africa, they will require Germany and South Africa type of industries to train students. Researchers believe that, this could be achieved through effective University-Industry collaboration and a lot of support from all stakeholders, as the current government is eager to support all types of industries to provide jobs for the youth and promote national development.

Evidence indicates that, in some developed and developing countries like Germany, China, Kenya, Chile and Colombia, Technical University students and industry continuously work closely together in applied, lifelong learning and research to equip students with industrial skills, promote innovation and National Development (Robinson 2012; Guimón 2013; Youssef, Y. Hunter, C. 2014). Results from Table 1 suggest that, students have a stock of rich theory knowledge of their subject areas which has to be merged with practical skills to accomplish industrial task to provide services for customers. Anything short of this, is not Technical University education as specified by the Ghana Government Technical University education policy, which describes Technical Universities as technological institutions with the sole responsibility of contributing actively to national development by providing career-focused education and skills training to the highest level possible and providing opportunities for applied research in close collaboration with the industry (Ministry of Education, 2014)

Technical University education has been designed in such a way that, for a student to graduate, he/she must be competent in both the theory and practical aspect of their areas of study. While the institution deals with the theory aspect, industry deals with the practical aspects to produce an individual capable of performing effectively in industry or establishing his/her business with the productive theory and practical knowledge acquired from the University and industry. To achieve this requires effective University-industry collaboration.

In Ghana, the issue of collaboration between Technical University education and industry has been a focus for politicians and academics (Okudzeto Ablakwa 2015; Nunfam et al 2015). Since Technical Universities have been granted autonomy and will have similar status to Universities, their efforts should be drawn not only towards teaching and research, but also to identifying opportunities for collaborating with industry and commerce (Ministry of Education, 2014). Effective collaboration with industry will not only benefit the students, as evidence suggested that effective partnership with industry generate funds to University, enhances staff capabilities which, in turn, reflect on the standard of teaching and research (Beard and Morton, 1999). The industry can also benefit tremendously from this partnership as they are the recipients of the best Technical University graduates (Nunfam et al. 2015). The University can share knowledge on new technology with industry and students also share theory knowledge by offering new ways and fresh minds of printing etc. The opportunity for students to gain work experience while they are studying is invaluable and industry collaborations for effective Industrial Attachment, is an example of how both industry and students can benefit from workplace experience (Lam \& Ching, 2006; Nunfam et al. 2015).

The lack of effective collaboration between Technical University/Polytechnics and industries in Ghana has been reiterated by numerous studies on Technical University education in Ghana over the years (Nunfam et al. 2015). Surprisingly, it appears very little has been done to improve the University-industry partnership to facilitate the provision of credible employability skills to students as required by the University curriculum.

Al-Ali (1992) argues that, mutual relationship between Technical University/Polytechnic and industry will facilitate the production of quality graduates for the community. Hence the need for the University and Industry to work hand in hand to effectively equip students with both theory and employability skills demanded by 
industry.

\section{Lack of Strategic Planning}

The second theme that came up during the analysis of the data was the lack of strategic management of the Industrial Attachment programme.

As Industrial Attachment is a mandatory requirement of the HND Graphic Design programme, participants agreed on the need for the designing of a careful plan of action to facilitate effective Industrial Attachment that will yield the desired outcome.

Participants were of the view that due to ineffective strategic management of the Industrial Attachment programme, they encountered several challenges including: Lack of attachment places, limited training time due to weeks or in some cases months of searching for an industry to train, limited industrial capacity and resources, look-warm attitude of industry and limited skill training among others.

In this study, the term strategic management is used as a plan of action that need to be put in place to ensure that students acquire employability skills during Industrial Attachment to help achieve the objectives of the programme, as well as the intended outcome for the students and the nation (UNESCO 2006).

The main objective of the Technical University Education is to "ensure hands down training and skills acquisition to meet the current needs of industry as a measure to accelerate the country's economic growth" (Okudzeto Ablakwa, 2015). The curriculum for this programme require students to obtain both theory and practical knowledge on their various specialities. While the University provides the theory aspect of the programme, industry is expected to provide the practical aspect.

The problem with this twin-method of acquiring knowledge in Ghana from different systems is that, while the University is well organized as an institution with adequate infrastructure, expertise and resources for the provision of continuous theory knowledge, the Graphic Design industry that provides the practical knowledge is not organized as an institution and most of these industries are small-scale in nature as seen from Table 10, where $87.5 \%$ of industries studied fall within this group. These small-scale industries also have limited capacity and resources as evident from Table 9 , where $62.5 \%$ of industries studied have limited resources and capacity, while Table 11 shows that about $25 \%$ of these companies provide limited specialized areas of Graphic Design.

This raises a lot of concerns about the quality of practical skills students get when compared with the theory knowledge in an organized institution. However, since this is the only means available to students, participants were of the view that strategic management of the Industrial Attachment programme should be put in place to ensure that every student could at least have the opportunity to train in all areas of their programme from small, medium and large-scale industries in the course of the three-year HND programme. Participants believed this would give all students equal opportunity in the acquisition of employability skills, as Table 9 revealed that, $62.5 \%$ of industries have limited resources and capacity for Industrial Attachment which suggest that, students who trained in these industries never had any opportunity to train in any well-resourced industry, thus limiting their chances of employment as suggested by results from Tables 5 and 6 .

The current Industrial Attachment programme requires an effective strategic management plan. This begins with a good understanding of the programme objective, which is to ensure that students acquire theory knowledge and hands down training and skills to meet the current needs of industry, as a measure to accelerate the country's economic growth (Kwami 2001; Ministry of Education 2010).

With this as the plan of action for Industrial Attachment, the arrangements for implementation, monitoring and evaluation should be the outcome of consensus agreed upon by all stakeholders contributing to the implementation of the intended plan (UNESCO 2006).

In the case of Takoradi Technical University, government provided the policy, whereas the National Board for Professional and Technician Examination helped with the contents of the curriculum. Industry is hardly consulted and if anything at all, only a few well-established industries who train only a few of the total number of students across Polytechnics and Universities in the country are involved. During the 23rd National Delegates Congress of the Ghana National Union of Polytechnic Students in Takoradi in 2015, Mr. Samuel Okudzeto Ablakwa, the then Deputy Minister of Education in charge of Tertiary Education stated that, "The Polytechnics are also to have Memoranda of Understanding between them and some selected industries" (Ghana Business News 2015). Why selected industries and not all industries involved in the industrial training exercise?

If only selected industries are consulted while others are not, then the result of such a plan could be the cause for the challenges students go through during Industrial Attachment. From the interview, participants explained that they found it very difficult to find placement and some of the industries are also very reluctant to train them. One participant stated that, "I was in one industry twice and always worked on the computer to make designs for customers.

My request to be allowed to observe the printing process on the printing machine was never granted" (ST 84).

Another participant explained that "we are always eager and excited to go on Industrial Attachment, with 
the dream of getting placement easily to help us understand all that we have been taught, but when we move from one large industry to another for days, weeks and at times months without success, we become very frustrated and eventually forced to settle for small scale industries with limited equipment and specialities for practical skills" (ST 5).

Participants also lamented that, the large number of Graphic Design students across tertiary institutions in the country vying for industrial placement compound the problem.

With a Strategic management plan in place, the current strengths and weaknesses of Industrial Attachment could be analysed. Based on the findings of the analysis from data on the programme, remedial options could be formulated and appraised. Measures could then be put in place to correct or improve the programme (Accra Polytechnic 2013; UNESCO 2006).

Though, evidence from this and other studies suggest that a good number of students acquire employability skills before graduation, a considerable number of students are not satisfied with the employability skills they obtain before they graduate, while employers are also not satisfied with the performance of graduates ((Adjei et al. 2012; Nunfam 2015). Students have been encountering these same problems every year since the establishment of the HND programme in 1992/1993 academic, yet, very little has been done to fully address them.

All stakeholders in the Technical University education need to understand that, in Technical University education, academic learning, though critical, is only part of the story as far as students and employers are concerned. Knowledge in Technical University education comes in the form of theory and practical and both are equally important to make students perfect in their respective specialities.

Although theory knowledge provides in-depth understanding of a concept, practical knowledge can often lead to a deeper understanding of a concept through the act of doing and personal experience (Bradley 2012).

Government decision to study the Germany system was a step in the right direction since Germany is one of the most successful economy in the world due to their Technical University education system. However, based on the practically demanding nature of Technical University education, one would have expected to know more about how they are successfully collaborating with industry, the nature and types of industry supporting Technical University education and how the programme is effectively being monitored to make it very successful. Unfortunately, the Technical Committee report was silent on these important issues.

According to Robinson (2012), the secret to Germany's strong economy and low youth employment rate is their value for making and fixing things (craft). He further explained that about two-thirds of German youth are involved in industrial work experience programme, making it easy for them to smoothly move from the education system to industry.

All hope is not lost for Ghana. There is light at the end of the tunnel for Technical University education in Ghana and can become like Germany our role model since the current government is determined to support the development of the private sector to drive wealth and national development.

To help students acquire the needed practical skills in the same way as the theory knowledge, the current Industrial Attachment programme need to be critically analysed to understand how it functions from the perspective of its strengths, weaknesses, opportunities and threats (UNESCO, 2006). This will help to identify challenges of the programme and to construct improved actions based on the goals of the programme.

Strategic management will also examine the significance, efficacy and effectiveness of the inputs, processes and outputs of the Industrial Attachment programme in its current state.

This process should then be followed by a plan of action on how the improvement is going to be implemented to achieve the desired goals of the programme for the students, employers and the country at large (UNESCO 2006; Accra Polytechnic 2013).

\section{Limitations of the Study}

It must be acknowledged that the term employability as used in this study was very limited in its scope and only concentrated on the acquisition of practical skills. However, further research, looking at the broader picture of employability of the entire Technical University education with good representation from all stakeholders is required.

\section{Conclusion}

In attempt to explore and understand the nature and forms of challenges obstructing the smooth provision of practical industrial skills to enhance student employability, this study identified two challenges hampering the effective acquisition of employability skills by students. These are ineffective collaboration between University and Industry and lack of strategic management of the Industrial Attachment programme. Failure to address these findings could deny students the ability to experience the practical skills they need for employment, make it difficult for them to be accepted on the job market and defeat the purpose of Technical University Education.

Researchers are of the view that, if collaboration between the Takoradi Technical University and Industry, 
as well as strategic management of the Industrial Attachment programme are effective, students will have industries to train, industries will be willing to train them, resources will be available to train them, they will be able to acquire all the employability skills needed and they will be readily accepted by employers.

\section{Recommendations}

- The University needs to create stronger industry links and ensure their students are equipped with adequate business-ready skills to enter a highly competitive market-place.

- To reduce these lapses, require effective University-Industry collaboration and effective strategic management of the entire programme with the support of all stakeholders in the University Education.

- Policy makers and the University need to regularly engage Industry to help design programmes that are relevant and alive to the needs of Industry and society.

- Government should use national resources to promote appropriate long-term partnerships between the University and Graphic Design Industry.

- Government to provide funds to Universities to evaluate the Industrial Attachment.

- Government to stimulate University-Industry collaboration by providing research grants and taxincentives for University and Industry to work together.

\section{REFERENCES}

1. Accra Polytechnic (2013) Strategic Plan 2013 - 2018 - Accra Polytechnic. Available from: www.apoly.edu.gh/sites/default/files/writeup.pdf · PDF file[Accessed 8 August 2017]

2. Adjei, A. K. N., Nyarko, D. A. \& Nunfam, V. F., (2012) Industrial Attachment in Polytechnic Education: An Approach to Polytechnic-Industry Nexus in Human Capital Development of Selected Polytechnics in Ghana. Available from: www.academia.edu/28430869/Industrial_Attachment_in_Polytechnic. [Accessed 30 May 2017]

3. Al-Ali, S. (1992) Polytechnics and industrial collaboration in the UK. Technovation Volume 12, Issue 7, Pages 459-464

4. Beard, F. and L. Morton, 1999. Effects of internship predictors on successful field experience. Journalism \& Mass Communication Educator, 53: 42-53.

5. Boahin, P. \& Hofman, A. (2013) A disciplinary perspective of competency-based training on the acquisition of employability skills. Journal of Vocational Education \& Training Volume 65, 2013 - Issue 3

6. Bradley, S. (2012) The Value of Theoretical and Practical Knowledge. Available from: vanseodesign.com > Blog > [Accessed 8 November 2017]

7. Bryman, A. (2016) Social Research Methods. Oxford University Press

8. Carbery, R. \& Garavan, T. (2005) Organisational restructuring and downsizing: issues related to learning, training and employability of survivors. Journal of European Industrial Training, Vol. 29 No. 6, pp. 488-508.

9. Creswell J.W., Plano Clark V.L., Gutmann M.L. and Hanson W.E. (2003) Advanced mixed methods research designs Sage, Thousand Oaks

10. Creswell, J. \& Plano-Clark, V. Designing and conducting mixed methods research. Sage, Thousand Oaks; 2007.

11. Creswell, J. W., \& Plano Clark, V. L. (2011). Designing and conducting mixed methods research. (2nd ed.). ThousandOaks, CA: Sage

12. Creswell, J. W. (2012) Qualitative Inquiry and Research Design: Choosing Among Five Approaches SAGE Publications

13. Doern B, (2008) Polytechnics" in Higher Education Systems: A Comparative Review and Policy Implications for Ontario Report. Available from: www.heqco.ca /.../Polytechnics\%20in\%20Higher\%20Education\%20Systems_A\%20Co [Accessed 8 August 2017]

14. Ghana Business News (2015) Conversion of polytechnics into Universities not a rebranding exercise Ablakwa Available from:https://www.ghanabusinessnews. com /2015/09/02/conversion-of... [Accessed 17 May 2017]

15. GSS (Ghana Statistical Service) (2006) 2003 National Industrial Census Main Report: Phases I and II Report, Main Results and Methodology, Accra, October.

16. Guimón, J. (2013) Promoting University-Industry Collaboration in Developing Countries. World Bank Report, 2013

17. Hakim, C (1987) Research design: strategies and choices in the design of social research. Contemporary Social Research Series (13). Allen and Unwin, London, UK.

18. Harvey, L. (2000a) New realities: the relationship between higher education and employment. Tertiary Education and Management. 6, 3-17...

19. Hawkins, P. (1999) The Art of Building Windmills: Career Tactics for the 21 st Century: Written by Peter Hawkins, 1999 Publisher: Graduate into Employment Unit, UK 
20. Hillage, J. \& Pollard, E. (1998) Employability: Developing a Framework for Policy Analysis. Available from: www.employment-studies.co.uk/.../report-summary-employability-developing-frame. [Accessed 25 November 2016]

21. Kwami, F. O. (2001). Report of the technical committee on polytechnic education in Ghana.

22. Lam, T. \& L. Ching, 2006. An exploratory study of an internship program: The case of Hong Kong students. Hospitality Management, 26: 336-351.

23. 23. Ministry of Education, (2010) Government of Ghana Education Strategic Plan 2010 - 2020 ESP VOLUME 1 \& 2 - Strategies and Work Programme. Available from: www.moe.gov.gh/assets/media/docs/ESP2010-2020Vol2Final.pdf · [Accessed 2 August 2016]

24. 24. Ministry of Education (2014) Report of the Technical Committee on Convention of the Polytechnics in Ghana to Technical Universities. Available from: www.moe.gov.gh/.../docs/ConversionOfPolytechnicsToTUs_FinalReport.pdf · PDF file [Accessed 2 August 2016]

25. Nunfam, V. F., Adjei, A. K. N., Nyarko, D. A. \& Padi, A. (2015) Human Capital Development in Polytechnics in Ghana: Prospects of Industrial Attachment. Journal of Economics and Sustainable Development, Vol.6, No.16, 2015. Available at SSRN: https://ssrn.com/abstract=2656858 [Accessed 9 February 2017].

26. Robinson, N. (2012) Employment Challenges for Canadian Youth in a Changing Economy. Available from: https://www.ppforum.ca/sites/default/files/Nobina\%20Robinson.pdf [Accessed 12 September 2017]

27. Sorensen, C. (2014) How the German style of apprenticeships could be a model for Canada. Would the German way really work here? Available from: www.macleans.ca/...the-german-style-of-apprenticeshipscould...canada [Accessed 12 September 2017]

28. Tim (2006) cited in Misra, R. K. (2011) Employability Skills: The Conceptual Framework \& Scale Development. Available from: https://www.questia.com/library/.../employability-skills-the-conceptualframework-sca... [Accessed 22 August 2016]

29. UNESCO, (2006) Strategic Planning in Education: Some Concepts and Steps. Available from: unesdoc.unesco.org/images/0015/001501/150191e.pdf [Accessed 2 August 2017]

30. UNIDO, 2004 Defining Small and Medium Enterprises: a critical review iipccl.org/wpcontent/uploads/2015/03/Ajbals-17-28.pdf · PDF file

31. Walker II, R.B., 2011. Business internships and their relationship with retention, academic performance, and degree completion. Unpublished PhD dissertation, Iowa State University, Graduate Theses and Dissertations. Paper 12015. Available from: www.aessweb.com/pdf-files/ijass 3(3)-783-799. pdf · PDF file [Accessed 25 October 2017].

32. Walliman, N. (2011). Research methods: The basics. New York: Rout ledge.

33. Yorke M. (2004) Learning \& Employability: Employability in higher education: what it is - what it is not. Available from: https://www.heacademy.ac.uk/knowledge-hub/employability-higher... [Accessed 20 October 2017]

34. Youssef, Y, \& Hunter C. (2014) Polytechnic Education in Canada: Reflections on a New Model. Available from: https:/www.researchgate.net/.../ 305777029_Polytechnic_Education _in_Canada_Reflection [Accessed 12 September 2017]

35. Yin, R. K. 1989. Case study research: Design and methods. Applied Social Research Series, Vol. 5. London: Sage 